\title{
Effect of Structural Relaxation on Mechanical Behavior of a Zr-Based Bulk-Metallic Glass
}

\author{
W. H. Jiang ${ }^{1, *}$, F. X. Liu ${ }^{1}$, H. Choo ${ }^{1,2}$ and P. K. Liaw ${ }^{1}$ \\ ${ }^{1}$ Department of Materials Science and Engineering, The University of Tennessee, Knoxville, Tennessee 37996, USA \\ ${ }^{2}$ Materials Science and Technology Division, Oak Ridge National Laboratory, Oak Ridge, Tennessee 37831, USA
}

\begin{abstract}
Using the instrumented nanoindentation and differential-scanning calorimetry, the effect of the structural relaxation at the elevated temperature on the $\mathrm{Zr}_{52.5} \mathrm{Cu}_{17.9} \mathrm{Ni}_{14.6} \mathrm{Al}_{10.0} \mathrm{Ti}_{5.0}$ bulk-metallic glass was investigated. The structural relaxation did not exert a significant influence on the plastic-flow behavior. However, the relaxation enhanced both the hardness and elastic modulus substantially. The decrease in the structural relaxation enthalpy before the glass transition indicates that the relaxation reduced the free volume significantly. The increase in the hardness and elastic modulus is attributed to the reduction in the free volume that resulted from the relaxation. [doi:10.2320/matertrans.MJ200734]
\end{abstract}

(Received November 14, 2006; Accepted January 19, 2007; Published June 25, 2007)

Keywords: bulk metallic glass, structural relaxation, mechanical properties

\section{Introduction}

During the last decade, a significant advancement has been made in exploring multicomponent glass-forming metallic alloys with substantially sluggish crystallization kinetics, which resulted in the development of numerous bulk-metallic glasses (BMGs), that include Zr-, Ni-, Ti-, Mg-, Cu-, Pt-, Fe-, $\mathrm{La}-$, and Pd-base alloy systems. As their critical cooling rates are as low as $100 \mathrm{~K} / \mathrm{s}$, the BMGs can be produced using conventional casting techniques and their size is as large as millimeters or even centimeters. ${ }^{1)}$ This progress makes the applications of metallic glasses as structural materials become a reality. ${ }^{1}$ The BMGs have outstanding mechanical properties, such as the high strength of up to $5 \mathrm{GPa},{ }^{2)}$ large elastic deformation limit of around $2 \%,{ }^{1)}$ as well as good fatigue properties. ${ }^{3-6)}$

As well known, metallic glasses are in a thermodynamic metastability and their structures tend to relax, by releasing the excessive free volume. The free volume as a structural feature in metallic glasses affects mechanical properties. A decrease in the free volume generally increases the strength and deteriorates the ductility. ${ }^{7-12)}$ But, the effect of the free volume on the mechanical behavior is seldom investigated experimentally.

Due to the shear-banding instability during the inhomogeneous deformation of BMGs, a very limited plasticity can be developed before the failure in a uniaxial loading. ${ }^{13,14)}$ This trend makes it difficult to investigate the mechanical behavior. An instrumented nanoindentation is a useful probe for studying the mechanical response of various materials to micro- to nano-scale loads. This technique has been applied widely to the investigation of mechanical behavior of metallic glasses. ${ }^{15)}$

In this paper, an instrumented nanoindenter is utilized to study the mechanical behavior of the as-cast and relaxed $\mathrm{Zr}_{52.5} \mathrm{Cu}_{17.9} \mathrm{Ni}_{14.6} \mathrm{Al}_{10.0} \mathrm{Ti}_{5.0}$ (atomic percent, at\%) BMGs. It is expected that this work can provide insight to the effect of structural relaxation on the mechanical behavior of the BMGs.

\section{Experimental}

The $\mathrm{Zr}_{52.5} \mathrm{Cu}_{17.9} \mathrm{Ni}_{14.6} \mathrm{Al}_{10.0} \mathrm{Ti}_{5.0}$ BMG (Vitreloy 105) was prepared by arc-melting a mixture of the constituent elements in a purified argon atmosphere. In order to obtain the homogeneity, the alloy ingots were remelted several times before cast into a water-cooled copper mold using an in-situ suction-casting facility. The resulting cylindrical BMG rods have a dimension of $3 \mathrm{~mm}$ in diameter and $30 \mathrm{~mm}$ in length. The specimens for the relaxation annealing were sealed in a quartz tube under vacuum. The annealing treatment was performed at $583 \mathrm{~K}$ for $30 \mathrm{~min}$., which is lower than the glasstransition temperature $\left(T_{\mathrm{g}}\right)$. The amorphous structure of the as-cast and the relaxed specimens was examined by $\mathrm{x}$-ray diffraction with $\mathrm{Cu} \mathrm{K} \alpha$ radiation using Philips X'pert Diffractometer. Differential-scanning calorimetry (DSC, Perkin-Elmer DSC7) was used to characterize the thermal properties of the BMGs. DSC was run two times for each specimen from 323 to $873 \mathrm{~K}$ at the heating rate of $20 \mathrm{~K} / \mathrm{min}$ in an argon atmosphere. Taking the second scan as a base line, any thermal effects from the structural evolution during heating were investigated.

The surfaces of the specimens were electropolished, using a twin-jet thinning electropolisher for nanoindentation tests. The polishing was performed at a solution of $25 \%$ nitric acid and $75 \%$ methanol (volume percent) at $243 \mathrm{~K}$ and a voltage of $10 \mathrm{~V}$. Nanoinstruments Nanoindenter II with a Berkovich diamond indenter was used to characterize their mechanical behaviors. At least 10 indents were made on each specimen with the separation between adjacent indents of $20 \mu \mathrm{m}$. The loading phase of indentation was carried out under the displacement control at the loading rates of $1 \mathrm{~nm} / \mathrm{s}, 10 \mathrm{~nm} / \mathrm{s}$, and $100 \mathrm{~nm} / \mathrm{s}$ to a maximum displacement of $350 \mathrm{~nm}$. At $90 \%$ unloading, a dwell period of $100 \mathrm{~s}$ was imposed to correct for any thermal drift in the system, which was less than $0.5 \mathrm{~nm} / \mathrm{s}$. The load-displacement curves, hardness, and elastic modulus were obtained from the indentation experiments. 


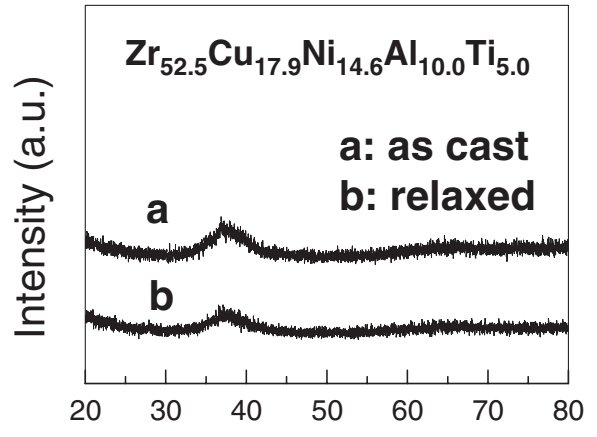

$2 \theta$

Fig. 1 X-ray diffraction patterns of the as-cast and relaxed $\mathrm{Zr}_{52.5} \mathrm{Cu}_{17.9}$ $\mathrm{Ni}_{14.6} \mathrm{Al}_{10.0} \mathrm{Ti}_{5.0}$ BMGs.

\section{Results}

Figure 1 shows the $\mathrm{x}$-ray diffraction patterns of both the as-cast and relaxed $\mathrm{Zr}_{52.5} \mathrm{Cu}_{17.9} \mathrm{Ni}_{14.6} \mathrm{Al}_{10.0} \mathrm{Ti}_{5.0}$ BMGs. The broad diffraction maxima demonstrate the amorphous structure of the as-cast and relaxed alloys. The relaxation annealing at the low temperature $(583 \mathrm{~K})$ for a short time ( 30 min.) only relaxed the amorphous structure and did not cause any crystallization.

Figure 2 displays the DSC thermograms for the as-cast and relaxed alloys that were normalized using the base lines. From the DSC curves, the typical thermal properties were determined, as shown in Table 1 . The as-cast and relaxed alloys exhibit a similar thermal behavior. There are an obvious exothermic peak for crystallization and an endothermic peak for a glass transition for both alloys. The exothermic heats of crystallization $\left(\Delta H_{\mathrm{x}}\right)$ are $47.6 \mathrm{~J} / \mathrm{g}$ and $42.5 \mathrm{~J} / \mathrm{g}$ for the as-cast and relaxed alloys, respectively, indicating their fully amorphous structures. The glasstransition temperatures $\left(T_{\mathrm{g}}\right)$ and the onset temperature of the crystallization $\left(T_{\mathrm{x}}\right)$ are $673 \mathrm{~K}$ and $744.7 \mathrm{~K}$, and $680 \mathrm{~K}$ and $741.5 \mathrm{~K}$ for the as-cast and relaxed alloys, respectively. The relaxation annealing stabilizes the structure of the alloy and delays the glass transition to a higher temperature. Figure 2(B) exhibits the enlarged DSC scanning curves at low temperatures. The exothermic reactions of both the ascast and relaxed alloys manifesting structural relaxation are clearly observed just below the $T_{\mathrm{g}}$. The structural-relaxation exothermic heat $\left(\Delta H_{\mathrm{o}}\right)$ of the as-cast alloy $(4.3 \mathrm{~J} / \mathrm{g})$ is much higher than that of the relaxed alloy $(1.6 \mathrm{~J} / \mathrm{g})$, which must be related to the large difference in the amount of the free volume between the as-cast and relaxed alloys. Slipenyuk and Eckert demonstrated that the amount of escaped free volume during heating is proportional to exothermic heat of structural relaxation. ${ }^{16)}$ Therefore, the relaxed alloy contains smaller amount of the free volume than the as-cast alloy.

Table 2 shows the values of hardness and elastic modulus of the as-cast and relaxed alloys that were obtained from the nanoindentation tests. It is important to mention that the hardness was obtained from the nanoindentation with a maximum displacement of $350 \mathrm{~nm}$ and a loading rate of $10 \mathrm{~nm} / \mathrm{s}$. Due to an indentation-size effect, hardness values for amorphous alloys, derived from nanoindentation, are higher than those obtained from macro- or microhardness
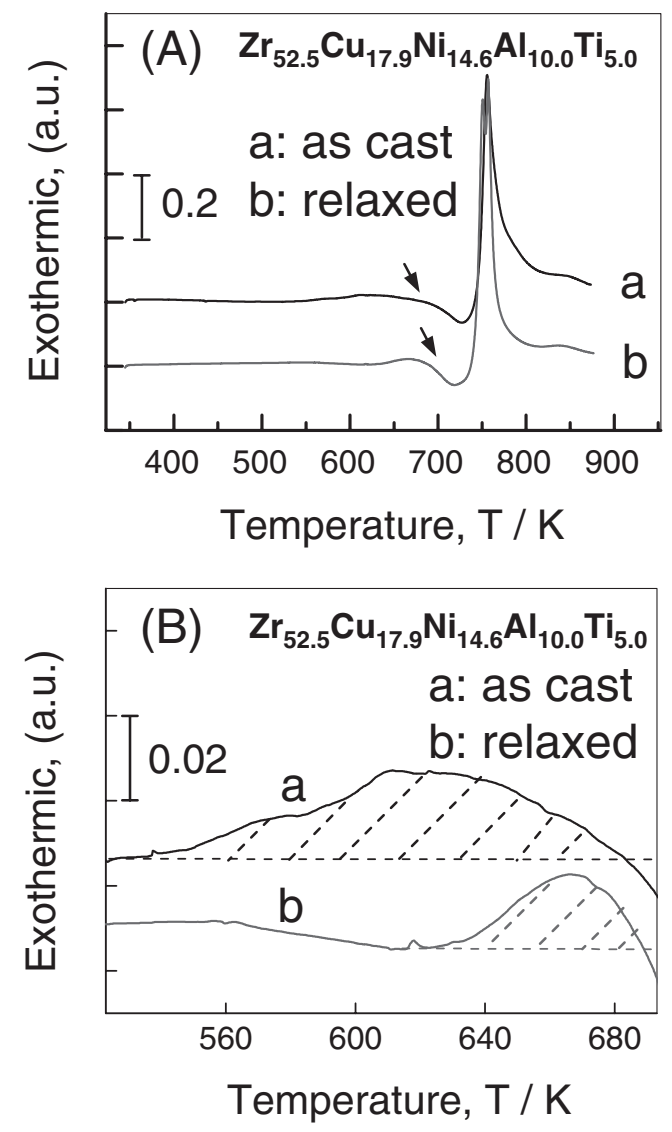

Fig. 2 (A) DSC traces of the as-cast and relaxed $\mathrm{Zr}_{52.5} \mathrm{Cu}_{17.9} \mathrm{Ni}_{14.6^{-}}$ $\mathrm{Al}_{10.0} \mathrm{Ti}_{5.0}$ BMGs at a heating rate of $20 \mathrm{~min} / \mathrm{s}$ and $(\mathrm{B})$ an enlarged portion of structural relaxation before the $T_{\mathrm{g}}$ in (A). The arrows in (A) indicate the $T_{\mathrm{g}}$.

Table 1 Thermal properties of the as-cast and relaxed $\mathrm{Zr}_{52.5} \mathrm{Cu}_{17.9^{-}}$ $\mathrm{Ni}_{14.6} \mathrm{Al}_{10.0} \mathrm{Ti}_{5.0}$ BMGs measured from DSC. $T_{\mathrm{g}}$ denotes the glasstransition temperature, $T_{\mathrm{x}}$ the crystallization temperatures, $\Delta T_{\mathrm{x}}$ the supercooled liquid region, $\Delta H_{\mathrm{o}}$ the structural-relaxation exothermic heat, and $\Delta H_{\mathrm{x}}$ the exothermic heat of the crystallization.

\begin{tabular}{ccccc}
\hline BMGs & $T_{\mathrm{g}} / \mathrm{K}$ & $T_{\mathrm{x}} / \mathrm{K}$ & $\Delta H_{\mathrm{o}} /(\mathrm{J} / \mathrm{g})$ & $\Delta H_{\mathrm{x}} /(\mathrm{J} / \mathrm{g})$ \\
\hline As-cast & 673 & 744.7 & -4.3 & -47.6 \\
Relaxed & 680 & 741.5 & -1.6 & -42.5 \\
\hline
\end{tabular}

Table 2 Hardness $(H)$ and elastic modulus $(E)$ of the as-cast and relaxed $\mathrm{Zr}_{52.5} \mathrm{Cu}_{17.9} \mathrm{Ni}_{14.6} \mathrm{Al}_{10.0} \mathrm{Ti}_{5.0}$ BMGs.

\begin{tabular}{ccr}
\hline BMGs & $H / \mathrm{GPa}$ & \multicolumn{1}{c}{$E / \mathrm{GPa}$} \\
\hline As-cast & $6.07 \pm 0.13$ & $87.40 \pm 0.76$ \\
Relaxed & $6.31 \pm 0.09$ & $100.85 \pm 2.33$ \\
\hline
\end{tabular}

testers. ${ }^{17,18)}$ Thus, the numbers we present here are only used for the comparison between the current two specimens. It can be seen that the relaxed alloy has a higher hardness and elastic modulus than the as-cast alloy.

Figure 3(A) displays the typical load-displacement curves for the as-cast and relaxed alloys at various loading rates. The obvious serrations are observed at all the loading rates for both alloys. The serrations become less obvious with increasing the loading rates for them. Such the strain-rate 

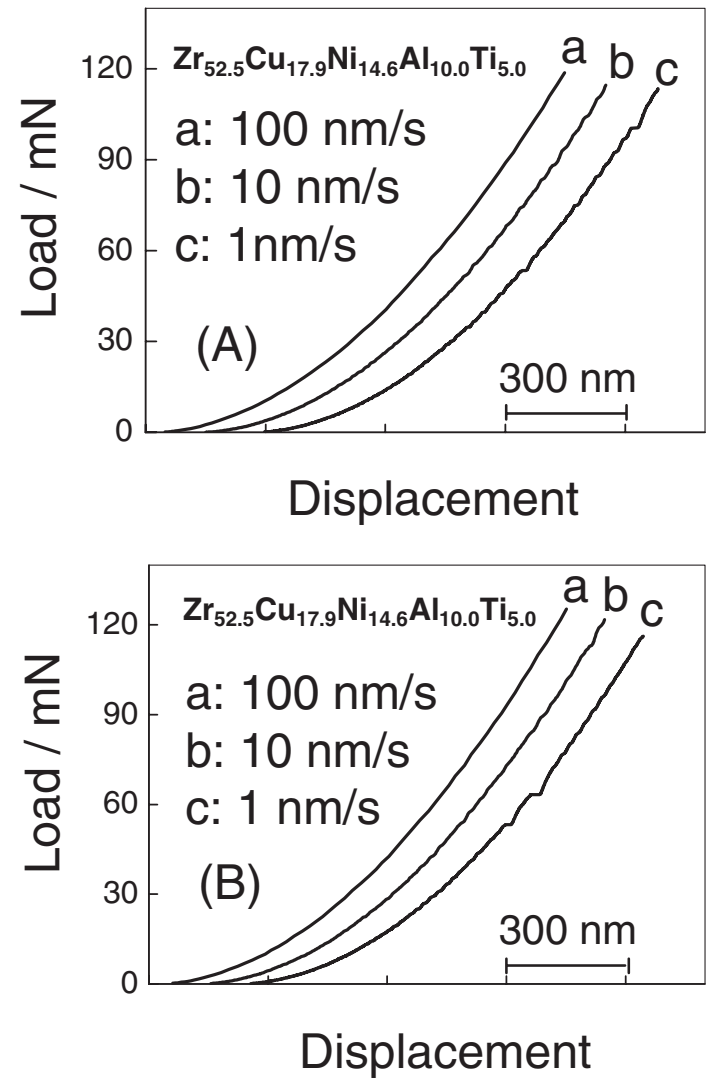

Fig. 3 The loading portions of the load-displacement curves for (A) the ascast and (B) the relaxed $\mathrm{Zr}_{52.5} \mathrm{Cu}_{17.9} \mathrm{Ni}_{14.6} \mathrm{Al}_{10.0} \mathrm{Ti}_{5.0}$ BMGs at various loading rates during nanoindentation. In order to avoid overlapping, the curves were shifted along the displacement.

dependence of the serrations is observed extensively in metallic glasses. ${ }^{15)}$ From the nanoindentation data, the strain rates, $\dot{\varepsilon}=(1 / h)(\mathrm{d} h / \mathrm{d} t)$, where $h$ is the indenter displacement during loading, were calculated for the loading rate of 10 $\mathrm{nm} / \mathrm{s}$. The values change with depth, as shown in Fig. 3(B). The strain rates for both the alloys show the same decreasing trend with increasing depth. However, the curves are not smooth and there are obvious serrations. These curves highlight the serration behavior observed in the loaddisplacement curves [Fig. 3(A)] and demonstrate that there is little difference in the serrations between the as-cast and relaxed alloys.

\section{Discussions}

Amorphous alloys contain a significant amount of free volume. The free volume is one of the most important structural features in amorphous alloys, which significantly affects the mechanical, physical, and chemical properties. DSC is one of the effective methods to characterize the structural relaxation that is closely related to the free volume in amorphous alloys, which is frozen during cooling. In a DSC thermogram, the exothermic reaction just below the $T_{\mathrm{g}}$ is a result of the annihilation of free volume and structural relaxation. The exothermic heat is proportional to the amount of escaping free volume. ${ }^{16)}$ The present work demonstrates that the exothermic heat during the structural relaxation in the relaxed $\mathrm{Zr}_{52.5} \mathrm{Cu}_{17.9} \mathrm{Ni}_{14.6} \mathrm{Al}_{10.0} \mathrm{Ti}_{5.0}$ is significantly smaller than that in the as-cast alloy [Table 1 and Fig. 2(B)], indicating that the relaxed alloy contains a smaller amount of free volume than the as-cast alloy. During cooling in the preparation of BMGs, a significant amount of excessive free volume is entrapped in an amorphous matrix. The free volume tends to escape, and at elevated temperatures, their kinetics becomes significant. Using DSC and density measurement, Slipenyuk and Eckert ${ }^{16)}$ demonstrated the decrease in the free volume that resulted from the relaxation annealing at the low temperatures. Even though a quantitative distinction in the free volume between the as-cast and relaxed alloys can not be made in the present work, a qualitative (or semi-quantitative) difference is clearly observed.

Nanoindentation indicates that the relaxed alloy has appreciably higher hardness and elastic modulus than the as-cast alloy (Table 2). Their difference in mechanical strength must be closely related to the amount of free volume in the amorphous matrix. Evidently, an increase in the free volume increases the average atomic distance that affects the material stiffness, i.e., elastic modulus. On the other hand, the free volume also influences the resistance to the plastic deformation. The increase in the free volume results in lower resistance to the plastic deformation. Jiang and Atzmon ${ }^{14)}$ also observed the decreases in the hardness values in the order of the as-relaxed, as-spun, and as-rolled states of the amorphous $\mathrm{Al}_{86.8} \mathrm{Ni}_{3.7} \mathrm{Y}_{9.5}$, while the free volume in these states is expected to increase in the opposite order. In fact, it is widely observed that relaxation annealing causes an increase in hardness/strength in metallic glasses. ${ }^{14-20)}$ The relatively high increase in hardness and elastic modulus of the relaxed alloy is attributed to the smaller amount of the free volume in its matrix, which was caused by the structural relaxation.

In nanoindentation, the load-displacement curves (Fig. 3) of both the as-cast and relaxed alloys display obvious serrations. Wright et al. suggested that the serrated plastic flow is caused by the formation of individual shear bands. ${ }^{21)}$ At low temperatures (e.g., room temperature) and high strain rates, metallic glasses exhibit an inhomogeneous plastic deformation, and the deformation is confined to highlylocalized narrow regions, i.e., shear bands. This trend indicates that the plastic deformation of both the as-cast and related alloys is inhomogeneous. However, the serrations tend to diminish with increasing the loading rates. Using atomic force microscopy, Jiang and Atzmon ${ }^{22)}$ observed the shear bands around the nanoindents for both higher and lower strain rates. With increasing strain rates, the shear bands become finer in size and larger in the number. They suggested the contributions to the absence of serrated flow at high strain rates: (i) the sampling rate, (ii) the instrumental response time, and (iii) the rate of shear-band formation. Using an infrared camera, Jiang et al. ${ }^{23,24)}$ recently observed in-situ dynamic shear-banding processes during uniaxial compression of the $\mathrm{Zr}_{52.5} \mathrm{Cu}_{17.9} \mathrm{Ni}_{14.6} \mathrm{Al}_{10.0} \mathrm{Ti}_{5.0}$ BMG and demonstrated that serrations in plastic flow correspond to the individual shear-banding events. No appreciable distinction in serrations between the as-cast and relaxed alloys can be made in the strain rate versus displacement curves (Fig. 4). Therefore, the effect of the free volume on the inhomogeneous plastic flow can not be identified in the present study. 


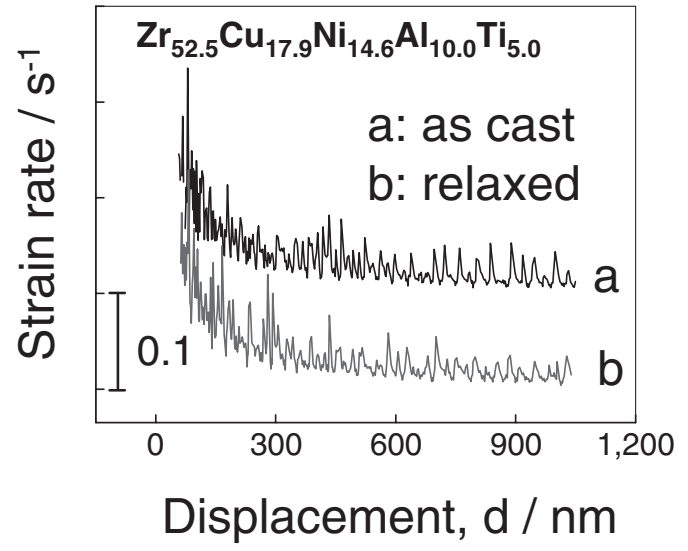

Fig. 4 The strain rate versus displacement curves for the as-cast and relaxed $\mathrm{Zr}_{52.5} \mathrm{Cu}_{17.9} \mathrm{Ni}_{14.6} \mathrm{Al}_{10.0} \mathrm{Ti}_{5.0}$ BMGs during loading at a loading rate of $10 \mathrm{~nm} / \mathrm{s}$. In order to avoid overlapping, the curves were shifted along the strain rate.

\section{Conclusions}

The as-cast and relaxed $\mathrm{Zr}_{52.5} \mathrm{Cu}_{17.9} \mathrm{Ni}_{14.6} \mathrm{Al}_{10.0} \mathrm{Ti}_{5.0}$ BMGs were characterized for the thermal and mechanical behaviors. The main results can be summarized as follows.

(1) The relaxation annealing at the low temperature and for a short time reduced the excessive free volume significantly.

(2) The structural relaxation enhanced both hardness and elastic modulus, which is attributed to the reduction in the amount of the free volume in the amorphous matrix.

(3) The as-cast and relaxed alloys exhibit a similar plasticflow behavior and strain-rate dependence during nanoindentation tests.

(4) The hardness and elastic modulus seem to be more sensitive to the amount of the free volume than the plastic-flow behavior in the $\mathrm{Zr}_{52.5} \mathrm{Cu}_{17.9} \mathrm{Ni}_{14.6} \mathrm{Al}_{10.0} \mathrm{Ti}_{5.0}$ BMG.

\section{Acknowledgements}

This work was supported by the National Science Foundation [NSF] International Materials Institutes [IMI] Program [DMR-0231320], the Combined Research and
Curriculum Development [CRCD] Program [EEC0203415], and the Integrative Graduate Education and Research Training [IGERT] Program [DGE-9987548] with Dr. C. Huber, Ms. M. Poats, Dr. C. J. Van Hartesveldt, Dr. D. Dutta, Dr. L. Clesceri, Dr. W. Jennings, and Dr. L. Goldberg as the Program Directors.

\section{REFERENCES}

1) W. L. Johnson: MRS Bull. 24 (1999) 42.

2) A. Inoue, B. L. Shen, H. Koshiba, H. Kato and A. R. Yavari: Nature Mater. 2 (2003) 661

3) W. H. Peter, P. K. Liaw, R. A. Buchanan, C. T. Liu, C. R. Brooks, J. A. Horton, C. A. Carmichael and J. L. Wright: Intermetallics 10 (2002) 1125 .

4) W. H. Peter, R. A. Buchanan, C. T. Liu and P. K. Liaw: J. Noncrystalline Solids 317 (2003) 187.

5) G. Y. Wang, P. K. Liaw, A. Peker, B. Yang, M. L. Benson, W. Yuan, W. H. Peter, L. Huang, A. Freels, R. A. Buchanan, C. T. Liu and C. R. Brooks: Intermetallics 13 (2005) 429.

6) G. Y. Wang, P. K. Liaw, W. H. Peter, B. Yang, M. Freels, Y. Yokoyama, M. L. Benson, B. A. Green, T. A. Saleh, R. L. McDaniels, R. V. Steward, R. A. Buchanan, C. T. Liu and C. R. Brooks: Intermetallics 12 (2004) 1219.

7) A. Concustell, G. Alcalá, S. Mato, T. G. Woodcock, A. Gebert, J. Eckert and M. D. Baró: Intermetallics 13 (2005) 1214.

8) Z. Bian, G. He and G. L. Chen: Scripta Mater. 46 (2002) 407.

9) P. Murali and U. Ramaurty: Acta Mater. 53 (2005) 1467.

10) U. Ramaurty, M. L. Lee, J. Basu and Y. Li: Scripta Mater. 47 (2002) 107.

11) Z. H. Zhang and J. X. Xie: Mater. Sci. Eng. A 407 (2005) 161.

12) W. H. Jiang and M. Atzmon: Acta Mater. 53 (2005) 3469.

13) T. Mukai, T. G. Nieh, Y. Kawamura, A. Inoue and K. Higashi: Scripta Mater. 46 (2002) 43.

14) Z. F. Zhang, J. Eckert and L. Schultz: Acta Mater. 51 (2003) 1167

15) C. A. Schuh and T. G. Nieh: J. Mater. Res. 19 (2004) 46.

16) A. Slipenyuk and J. Eckert: Scripta Mater. 50 (2004) 39.

17) D. C. C. Lam and A. C. M. Chong: Mater. Sci. Eng. A 318 (2001) 313.

18) M. J. Mayo, R. W. Siegel, A. Narayanasami and W. D. Nix: J. Mater. Res. 5 (1990) 1073.

19) A. L. Greer: J. Non-crystalline Solids 61 \& 62 (1984) 737.

20) Y. Yokoyama, Y. Akeno, T. Yamasaki, P. K. Liaw, R. A. Buchanan and A. Inoue: Mater. Trans. 46 (2005) 2755.

21) W. J. Wright, R. Saha and W. D. Nix: Mater. Trans., JIM 42 (2001) 642.

22) W. H. Jiang and M. Atzmon: J. Mater. Res. 18 (2003) 755.

23) W. H. Jiang, G. J. Fan, F. X. Liu, G. Y. Wang, H. Choo and P. K. Liaw: J. Mater. Res. 21 (2006) 2164.

24) W. H. Jiang, G. J. Fan, F. X. Liu, G. Y. Wang, H. Choo and P. K. Liaw: Inter. J. Plasticity (In press). 